\title{
The Informal Sector and Women's Oppression
}

\section{Manfred Bienefeld}

\section{Introduction}

The relevance of the informal sector (IS) debate to a discussion of the special problems confronted by women in the development process, lies in the fact that both are concerned with groups subject to social and political discrimination and forced into the labour market equipped with relatively low levels of skill and formal qualification. Like the developing economies in the global context, both groups therefore bear an inordinate share of the burden associated with capitalist economies operating at less than full employment.

Analytically the most important characteristic distinguishing these two categories is the fact that women clearly constitute a physically defined category of labour made up of a particular set of individuals while the informal sector refers not to a specific set of individuals, but to that set of individuals whose labour is not required by capitalists for direct wage employment. In theory this means that while the problems of the informal sector can only, by definition, be resolved through full employment, those of women might be resolved by an improvement in their relative position, as a particular group of workers. In practice this difference has important implications both for analysis and for the formulation of appropriate policies or political objectives.

\section{The Informal Sector's Role in a Capitalist Economy}

The complex and often acrimonious debate over the role played by the informal sector in developing economies rests on a basic disagreement about the prospects for capitalist full employment. In essence there are three points of departure for the various formulations held. The first considers global capitalist full employment to be a realistic prospect in the forseeable future; the second believes full employment within particular capitalist nation states to be feasible; the third sees capitalist full employment as a necessarily partial and temporary condition which can neither be sustained, nor generalised, and which is a particularly remote possibility in the underdeveloped countries.

In a formal sense, the feasibility of capitalist full employment must play, a central role in determining the way in which the informal sector is perceived, as soon as the latter is defined as labour not yet directly absorbed into capitalist production. However, the connection between the level of employment and the position of wage labour in a capitalist economy is worth considering in more general and substantive terms.

Full employment is a critical determinant of the social consequences of competitive economic mechanisms. In a competitive economy the wage is determined by the supply and demand for labour, and when labour is in excess supply the competitive process will tend to force wages down. Furthermore, it will continue to do so until arrested in one of three ways: by the establishment of full employment; by reaching an 'efficiency wage level', (defined as that level of wages beyond which, because of adverse effects on productivity, further reductions will increase unit labour costs); or by generating social and political forces which restrict the competitive principle, and introduce so-called 'market imperfections'. With these exceptions, the downward pressure on wages recognises no limits, nor in the absence of full employment is this pressure eased by the fact that technical progress may have raised average productivity to historically high levels. Such productivity increases do not by themselves increase real wages, they merely accelerate accumulation. Within the logic of the system real wages for the labour force as a whole are increased only by the emergence of a general scarcity of labour, though of course high average productivity levels may help to ensure the accumulation required to produce such a labour constraint. On this aspect of the wage question there is agreement between neo-classical and classical (both Ricardian and Marxian) economics.

It follows then that the relatively benign form of capitalism associated with the industrial countries is that of full employment capitalism. Such a capitalism disperses material benefits to the mass of its population, and accelerates technical progress by concentrating the search for competitive advantage on technical change. Furthermore, if capitalism could permanently take this form in the developing countries it could be expected to produce similar results there. The substantial rise of unskilled real wages in South Korea in the 1970s, which occurred even though the weak trade unions were controlled by an authoritarian, growthoriented state, provides the most recent evidence in support of this argument.

Returning to the informal sector debate, it can now be seen that for anyone who believes in the present 
possibility of global capitalist full employment. and who therefore also believes that existing market and institutional structures are effective in channelling and reinvesting profits. low wages are bound to appear egalitarian and progressive. since they contribute to accumulation. and bring closer the day when everyone is incorporated into the capitalist structure. Indeed it is only at that point that the diffusion of material benefits can begin without undermining growth and without discriminating against those sections of labour still left outside the system.

The informal sector debate challenged this perspective in the early 1970 s. precisely because the explosive urban growth in the developing world demonstrated the existence of a large pool of labour which the capitalist sector could not absorb in the foreseeable future. One way of dealing with this problem was to consider the "informal sector" as a separate sphere of activity which. rather like the non-capitalist subsistence sector in the 'Lewis model' (Lewis 1954). acted as a labour reservoir releasing its labour to the expanding capitalist sector as required. while through its income opportunities, establishing a lower limit to the capitalist sectors unskilled wage. Unfortunately. if it was a 'separate' sphere. its internal developments would not be guided by market signals. so that their impact on capitalist accumulation would be unpredictable and generally problematic. especially because improvements in the sectors productivity would impede accumulation by raising wages. The identical problems presented by the Lewis model's 'subsistence sector'. had been shown to be resolvable in theory. if that sector could be transformed into a capitalist agricultural sector | Ranis and Fei 1961।. Naturally the informal sector debate soon began to consider how this sector could be similarly integrated into the overall process of capitalist accumulation.

A theoretical solution to the problem was to hand once one established that it was possible. and indeed necessary. to consider the informal sector as an integral part of the process of capitalist accumulation. since it was almost certainly more freely competitive than the rest of the economy, its products circulated within open domestic markets. and its labour force moved relatively freely within the domestic economy. If capital did not move so freely this might simply reflect a rational response to the high risks and low profit margins associated with these forms of production. This resolved all problems for the theoreticians. if not for the people in the shanty towns. There was now no massive unemployment. since the allegedly unemployed labour was working in the informal sector. Furthermore. the informal sector was no problem since in many respects it made the best possible use of the labour available [ILO 1972]. Furthermore. since it was so closely integrated with the capitalist sector. its low wages were just as much a regrettable but ultimately desirable necessity. as were the low wages in the capitalist sector. which. indeed. they helped to define [Fitzgerald 1976].

When such analytic perspectives were combined with a fervent desire to achieve rapid change. attention turned to efforts to assist those in the informal sector to become accumulating capitalists through training. or credit or other forms of concrete assistance. and although in some cases it was recognised that this would inhibit accumulation by the existing owners of capital [ILO 1972]. there was generally too little recognition of the macro-economic policies required to make such an option feasible. This related especially to the need to reconcile the capitalist sector 's exposure to international competitive pressures with the proposed 'national policies. even if these were feasible in terms of domestic political forces.

In general the resulting efforts were based on the misconceived idea that the improvements sought could be affected within the existing macro-economic frame. and that the informal sector was constituted by the particular individuals found within it at any one time. whose condition one needed to improve /Sethuraman 1976]. Not surprisingly. the consequent policies could never escape the charge that they were merely helping some individuals at the expense of others. or that they were shifting resources towards less efficient uses. to the detriment of the overall process of accumulation. Indeed. within this frame of analysis. the charge of resource misallocation could only be effectively rejected if it could be shown that the proposed resource shifts represented a removal of existing 'market imperfections". reflecting political discrimination against the informal sector | ILO 1972].

To conclude. given a belief in the efficacy of the market. and in the reasonable prospect of global full employment. the informal sector. viewed as an integral part of the competitive economy. merely appears as a particular. and indeed appropriate. form for capital to utilise labour when that capital is very scarce in relation to labour. The fact that such activities yield low income either indicates the existence of market imperfections. or reflects their low productivity. The only real solution to that problem is therefore to remove the imperfections and to assist the process of accumulation by leaving incomes to be determined strictly by the market. If in fact global competitive pressures did drive wages - and through them informal sector incomes-down below the level of subsistence. then the resultant problem had to be seen primarily as one of over-population. 
But the view of the informal sector changes dramatically if global full employment is not seen as a realistic possibility in the foreseeable future. either because it is simply too remote. or because the global process of accumulation is too imperfect or uneven for its general realisation. Nor does it matter. at this stage in the argument. whether this is true because of 'market imperfections' involving the use of political and market power to concentrate the process of accumulation in certain locations (countries). or because the importance of technical change as a means of reproducing competitive advantages was so great that the competitive process itself produced an increasing concentration of capital. Probably in the real world both of these mechanisms have been important. so that the logic of the market and the effect of 'market imperfections' have been mutually reinforcing.

From such a perspective low wages in the developing countries appear as exploitative shackles binding workers to a system which produces benefits for others. primarily members of the bourgeoisie who derive their consumption funds out of the accumulated surplus. but also including other groups in 'protected' parts of the global labour market. Hence those in the informal sector. along with the weakest. lowest paid sections of the labour force. appear trapped in a situation where their sacrifices will not help to solve their problems. All that is possible under these circumstances is for a few individuals to "escape into capitalist accumulation. or into some protected labour market through emigration. the acquisition of some skill. or luck.

Now exhortations to work harder, or the justifications of low wages as a necessary requirement for accumulation and eventual full employment. appear as specious arguments designed to justify a system whose material benefits accrue primarily to those who control it. The same is true of the benefits of improved efficiency. which will also. at best. allow a few individuals to escape, which may. however. be important since so long as such escape is thought to be possible. the intense competitive pressures within the informal sector will limit the emergence of solidarity. in support of more general solutions. especially since these will be necessarily slow and uncertain.

But where does this second perspective lead. analytically or politically? It is. after all. hardly adequate merely to show why certain types of policies are unlikely to resolve the problems at which they are directed. It is necessary rather to pursue the argument to the point where it helps to clarify the objectives worth arguing. or struggling for. The result will depend on the extent to which full employment nationally is seen as either a feasible or a desirable objective. Both historically and theoretically there are good reasons for considering this to be a genuine alternative. although given current high levels of global unemployment. there is wide disagreement over the mechanisms by which it might be realised.

Within a capitalist context. such a possibility requires policies designed to initiate a nationally concentrated process of accumulation which makes use of domestic and foreign resources to create a production structure simultaneously capable of producing full employment. maintaining its external accounts in balance and developing a technological capacity capable of sustaining competitiveness even when real wages begin to rise. The rare cases of Japan. and of South Korea in the $1970 \mathrm{~s}$. suggest that this requires a powerful state capable of imposing a long-term national rationality on investment patterns. through nationally controlled financial. industrial and trade structures. although tiny economies like those of Hong Kong or Singapore suggest that in their case such requirements are less strict.

The nature and degree of state intervention required to achieve such objectives at the present stage of capitalism s global evolution cannot be further discussed in the context of this brief paper. Suffice it to say that the range of possibility extends all the way from the South Korean to the North Korean models. and may well conform to the principle that the more remote capitalist full employment is thought to be. the more extensive is the range of potentially beneficial forms of state intervention. Indeed. if sustained permanent full employment is not just seen as temporarily unattainable. but is deemed impossible under capitalism. then this provides the basis for a move away from capitalism. and a removal of private capital as the central actor in the process of accumulation and resource allocation.

It is these underlying perspectives which account for the extraordinary extent of disagreement in a debate ostensibly concerned with the phenomenon of smallscale production. While from all points of view the encouragement and improved efficiency of smallscale production is potentially of great significance. it is one's perception of the context within which such efforts are undertaken. which will determine whether they improve the welfare of the groups in question. even if they do increase productivity.

Given these wide disagreements which are reflected in the debate there is nevertheless a considerable common ground for all those who consider that the present impossibility of full employment in most developing countries requires special policies aimed at maximising aggregrate production while preventing minimum wages from falling below some socially and politically defined minimum. Since this cannot be 
done by simply legislating minimum wages. it can only be done by providing (if possible). the as yet unincorporated labour with productive assets. so as to allow that labour power to be utilised optimally in a self-employed context [ Lipton 1980\}. For such labour. incomes would be determined by their average product. rather than by their 'marginal product' in an oversupplied labour market. The opposition to such policies comes from the fact that they raise the minimum wage in the capitalist sector and hence reduce the rate of accumulation of the present owners of capital. Even so this need not reduce overall accumulation in the economy. since these self-employed producers would. in the course of their operation. effectively create capital which could more than offset the losses incurred elsewhere. Such small producers could thus make a net addition to capital accumulation. always provided that the environment in which their growth had been fostered was maintained, and their 'assets' were not destroyed by their sudden exposure to competition from technically. or economically, much more powerful rivals |Bienefeld 1975|. The problem is that while a national policy protecting domestic capitalists from international competition is sometimes a feasible proposition. a similar policy. within a nation. to protect petty producers from domestic capitalists is more difficult to imagine. especially if these domestic capitalists are themselves subject to competitive pressures from abroad. through commodity. money or capital markets.

\section{Women in the Labour Market}

For women in the labour market the problems are similar. with two significant differences. First. since they constitute a specific group. their problems could in theory be resolved without even the attainment of full employment at the national level. Secondly. they suffer a degree of social oppression. which is superimposed on their difficulties in the labour market. and which means that they are often the first to suffer from unemployment. and even when there is full employment. they may actually be prevented from enjoying its full benefits.

It is this duality which gives women's struggles their particular and complex character. so that they continue when there is full employment. as in the industrialised countries in the $1960 \mathrm{~s}$, and even when labour power is no longer sold on the market. as in the socialist countries. At the same time. there can be no doubt that the economic context exerts a powerful influence over the possibility and the nature of these struggles and it is important to consider the complex relationships between these two arenas.

In general these two sources of oppression may be regarded as mutually reinforcing. with the social oppression of women being strengthened by the difficulties they encounter in obtaining employment and by the poorer conditions they must endure when they do find it. Thus the social and economic struggles of women cannot be separated. It remains essential that a primary objective must be the establishment of a state. capable of generating a socially desirable and dynamic process of accumulation which leads towards eventual full employment. but which in the meantime maintains a minimum wage floor. not through discriminatory legislation. but by facilitating the development of a dynamic small-scale production sector based on a dispersal of productive assets and gradually declining. though adequate. levels of protection.

Within such a context the overthrow of social oppression would become easier. Indeed. if full employment were eventually achieved. market forces would actually come to support the fight against social oppression. although this would by no means ensure its success. That does not imply. however. that the economic struggle should come first. to be followed by the social struggle when the former has succeeded. Rather the two must go hand in hand. In this sense the women's struggle must identify itself with the efforts of all those seeking to attack the problem of the informal sector. or of marginalised labour. at its roots.

In so far as this common objective is abandoned. what is left is the attempt to gain access to those jobs that are available. on whatever terms are on offer. by demanding equal access or by protecting some niche of the labour market for a particular group. The fact that such struggles may not produce general improvements does not mean they are insignificant. To the groups or individuals concerned they are most important. so important indeed that they often obliterate any concern with the broader issues. especially since the proposed solutions to these broader questions are complex. long-term. theoretical and disputed. while the gains from narrower 'economistic' struggles appear simple. concrete and clearly visible. even though they are in reality necessarily restricted to a few aspirants.

Such struggles between different groups of workers are welcomed and encouraged by capital as "healthy" competition in the labour market. and in them the market again displays its egalitarian side. Far from being in any direct sense a cause of women's social oppression. it is rather a force whose inner logic fights against that discrimination to make all equal before the law of value. Left to exert its influence, it will fill nineteenth century Manchester cotton mills. or twentieth century runaway electronics factories. with women (or children) even where women s access to jobs has been severely restricted by established custom. Unfortunately. so long as full employment remains 
unattainable. the result equalises working conditions for everyone. bar the labour aristocracies". but it equalises them by worsening them all.

A special problem arises if political struggle is able to induce the state to force the process of accumulation to operate alongside a small-scale productive sector based on labour-intensive self-employment. able to generate an average income which establishes a socially and politically viable floor to the capitalist wage. If within that informal sector. production is based for instance on the principles governing labour allocation in the subsistence rural household [Chayanov 1966]. or the so-called Family Mode of Production |Lipton 1980|. then within these 'economic units'. labour is not allocated according to marginalist principles applied to each individual as in a labour market. but will be more fully utilised in that it will be applied until production is maximised [Sen 1966|.

Now theoretically the 'economic unit in question need not be the household. or family. It could be a commune. a collective or some other socially constituted unit of joint production and consumption. but it cannot be the individual. In so far as it is desirable that in some sphere of production labour is utilised according to such alternative principles. it is. therefore essential to have viable economic units within which to apply these. Unfortunately it is hypothetical social units such as these which are the agencies of women s social oppression. whether these be the family. or the commune |White 1980|. This means that in those developing countries where even an ideally constituted process of accumulation could not hope to attain full employment in the foreseeable future. and where therefore such alternative patterns of labour use are likely to be desirable for accelerating accumulation and for providing a floor to the market wage. a choice needs to be made. If such an alternative is to be espoused. the need to establish some relatively equitable social and economic units on which it is to be based must be acknowledged. Otherwise the alternative must be rejected on the grounds that the degree of social oppression of women. inevitably associated with such units, is unacceptable. In that case there is, however. no way to devise an accumulation model which could avoid imposing heavy social and economic costs on the unskilled mass of the labour force. during the time required to reach full employment. Indeed this conclusion would also apply to a socialist economy incapable. in the short run. of providing all its members with employment opportunities based on the use of productive assets made available within a planned economic structure.

For different reasons a similar issue arises if we look at the labour market s logic in a full employment capitalist economy. ${ }^{\prime}$ Here too competitive markets would tend in principle to help the women s struggle break down socially constituted discriminatory barriers. Furthermore. in this case the consequence would be more desirable. since it would tend towards an equalisation of the conditions of labour. within a context of rising real wages. Here too there would be a problem. however. in that if this equality is achieved within a competitive market context. it will be achieved within the context of a further individualisation of society. In this sense it is important to question the idea so widely derived from Engels. that the bourgeois family is the necessary foundation of bourgeois capitalist society. In fact the advance of capitalism has involved the progressive breaking down of effective social units-from the community or clan. to the extended family, to the nuclear family. At the end of this process stands the individual and the logic of the system will not rest until each individual is fully and directly exposed to the dictates of the market. until

by the action of Modern Industry, all family ties among the proletarians are torn asunder. and their children transformed into simple articles of commerce and instruments of labour. |Marx and Engels 1848|.

Again, this is not a decisive argument. since women's oppression within the family may. in general, be deemed so intractable and pervasive, that such consequences are accepted as a lesser evil. or welcomed as a liberation. Even so it is important to recognise these implications clearly. and to consider the possibility that there may be an urgent need to combine the struggle for equality in the market, with a struggle for the constitution of some acceptable social unit, within which people could be encouraged to make lasting commitments and to build human relationships, protected from the short-term utilitarian and commercial calculus that otherwise threatens to drown all human and social relationships in its icy waters.

If this is not possible. all social relations are likely to be transformed into "arm's length" transactions between otherwise independent agents. All. that is. except those transactions effected within the ever expanding corporate units of production which are not arm s length in the economists jargon. but which are subject to the same utilitarian calculus. only now applied even more ruthlessly within the confines of a soulless and authoritarian institutional structure. Already many corporations are said to prefer divorced. or unattached people. as executives. because they will put the corporation first. on the grounds that they cannot afford people who maintain conflicting commitments.

\footnotetext{
The possibility of sustaining full employment under capitalism is not a subject for this discussion. although it clearly cannot be taken for granted.
} 
At the end of this process. each individual's identity will be defined in relation to his or her career or job. and that in turn will be defined by some corporate institution. demanding total commitment - on pain of expulsion from the corporate world and its material rewards.

For every one of us. but especially for those trapped in the hopeless labour markets of the developing world. the question is whether it is possible to construct viable social and political units which the market can serve. If that is not possible. then the most outrageous science fiction vision of the future may come true and the individualisation of society will proceed until not only our labour power. but our very bodies will become commodities. It is well to remember that slavery was destroyed by capitalism largely because it proved less efficient than free labour. and there is reason to believe that technology could change that outcome. Already there are schools in the United States where teenage children are given daily doses of drugs to reduce their "hyper-activity". and there are factories in South Africa and in various export processing zones where labourers live as individuals in closely controlled and even guarded dormitories. Who but a 'presumptuous' moralist. using (much derided) subjective and normative judgments. would say it was 'wrong' to bring these two concepts together, while increasing and diversifying the drugs administered? Certainly objections would be raised to such attempts. but if such forms of production proved more efficient. and if others had introduced them and were threatening jobs as a result. who can believe that they would not be reluctantly accepted. especially in view of the much acclaimed "benefits to the consumer"?

Like the genie in the fairy tale. the competitive principle has brought untold material wealth to many. but it will transform those gifts into the means of our enslavement if it cannot be made to serve some social purpose defined by people.

\section{References}

Bienefeld. M. A.. 1975. 'The informal sector and peripheral capitalism: the case of Tanzania: IDS Bulletin. vol 6 no 3. February

Chayanov. A. V.. 1966. The Theory of Peasant Economy. Irwin. Homewood. lllinois

Fitzgerald. E. V. K.. 1976. 'The urban service sector, the supply of wagegoods and the shadow wagerate. Oxford Economic Papers. 28.2

ILO. 1972. Employment, Incomes and Equality: a strategy for increasing productive employment in Kenva. Geneva

Lewis. W. A., 1954. 'Economic development with unlimited supplies of labour'. Manchester School, vol 26. May

Lipton. M. 1980. 'Family. fungibility and formality'. IDS, mimeo

Marx. K. and F. Engels. 1848. 'The Communist Manifesto'. in Marx and Engels. Selected Works. vol 1. Progress Publishers. Moscow

Ranis. G. and J. C. H. Fei. 1961. 'A theory of economic development. American Economic Review. September

Sen. A. K.. 1966. 'Peasants and dualism with or without surplus labour'. Journal of Political Economy. 74. pp 425450

Sethuraman. S. V.. 1976. 'The urban informal sector: concept. measurement and policy. International Labour Review. 114. 1 July-August

White. C.. 1980. 'Women and socialist development: reflections on the case of Vietnam. paper presented to Political Science Association Conference. Exeter University. April 